\title{
腰椎分離，変性迄り，分離过り症における術後長期成績について
}

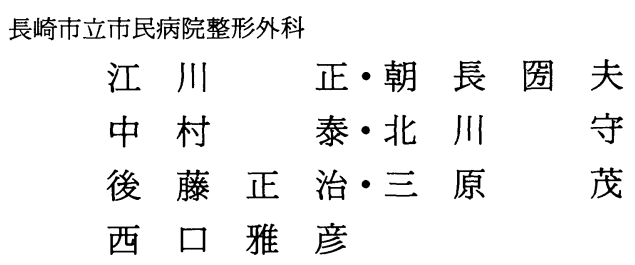

\section{The Post-Operative Evaluation of Spondylolysis, Degenerative Spondylolisthesis and Spondylolytic Spondylolisthesis in Adults - A Long-Term Follow-up -}

by

\author{
Tadashi Egawa, Kunio Tomonaga, Yasushi Nakamura, \\ Mamoru Kitagawa, Shoji Gotoh, Shigeru Mihara, \\ and Masahiko Nishiguchi \\ Department of Orthopedic Surgery, \\ Nagasaki Municipal Hospital
}

\begin{abstract}
Thirty-two patients ( 24 male, 8 female) had clinical and radiographic evaluation with an average follow-up of ten years and one month. (range 6-15 years)

The material consisted of 12 cases of spondylolysis, 10 cases of degenerative spondylolisthesis and 10 cases of spondylolytic spondylolisthesis. Ten cases of spondylolysis were treated with P. L. F. J 2 cases with P. L. F. and laminectomy, and all cases of deg. spondylolisthesis with P. L.F. and laminectomy. Seven cases of lytic-listhesis were treated with P. L.F. or P. L. F. and laminectomy, 2 cases with A.F. and laminectomy, and one case with laminectomy. An increase in the slip was recorded in $5 / 7$ cases in deg. spondylolisthesis and $4 / 9$ cases in lytic-listhesis.

Clinically, 28 cases $(87.5 \%)$ were evaluated as excellent or good, one case as fair, and 3 cases as poor. The spondylolytic group was evaluated as worse than the other two groups.
\end{abstract}

\section{はじめに}

不安定性腰椎として分離症, 変性り症および分離 沪り症の治療上に占める頻度は高く, 今日種々の治療 法が行われている。.今回われわれはかかる三疾患に対 し後側方固定術を主体とした手術症例の予後調査を行 ったので報告する。

\section{対 象 症 例}

昭和 50 年 1 月より 58 年末までに当科で手術を行い, 術後 6 年以上経過した 80 症例中, 今回直接検診し得た 男性 24 例，女性 8 例の計 32 症例である．手術時年令
は 17 オより 68 才にわたり十代 1 例, 二十代 3 例, 三 十代 6 例, 四十代 7 例, 五十代 14 例, 六十代 1 例で 50 才台がもっとも多くなっている. 疾患別では分離症 12 例, 変性过り症 10 例, 分離过り症 10 例であり, 各疾 患の平均年令は夫々 39.0 才, 52.3 才, 45.6 才で, 変性 匠り症群がもっとも高令である.

障害レベルは分離症群では全例 $\mathrm{L}_{5}$ レベルであり, 変 性之一症群では 10 例中 9 例が $\mathrm{L}_{4}$ レベルであり, 分離 方り症群では $\mathrm{L}_{4}$ レベル 4 例, $\mathrm{L}_{5}$ レベル 6 例と差異はな い. 手術時に椎間板へルニアの合併を認めたものが 5 例で, 分離症群々 3 例, 変性过り症, 分離之り症群に 各 1 例で迄り症群に多く,またへルニア高位は不安定 
表 1 疾患と術式

\begin{tabular}{l|c|c|c}
\hline \hline & -LYSIS & $\begin{array}{c}\text { DEG. } \\
\text { L I S T H- } \\
\text { ESIS }\end{array}$ & $\begin{array}{c}\text {-LYSIS } \\
\text { L I S T H. } \\
\text { ESIS }\end{array}$ \\
\hline $\begin{array}{l}\text { P. L.F. } \\
\text { P. L. F. + }\end{array}$ & 10 & & 3 \\
LAMINECTOMY & 2 & 10 & 4 \\
$\begin{array}{l}\text { A. F.+ } \\
\text { LAMINECTOMY }\end{array}$ & & & \\
LAMINECTOMY & & & 2 \\
\hline
\end{tabular}

椎の上位隣接椎間に 3 例, 不安定椎間に 2 例となって いる.

術後経過年数は最短 6 年 2 カ月より最長 15 年で平 均 10 年 1 力月であり, 10 年以上の症例が $56.3 \%$ を占 めている. 術式では分離症群は 2 例を除き大部分が後 側方固定のみであり, 変性过り症群では全例椎弓切除 に後側方固定術が併用されている。また分離沪り症群 では症例により種々の術式が行われているが, 大多数 は後側方固定術またはこれに椎弓切除術が併用され， その他 2 例に前方固定と椎弓切除術が，他の 1 例には 椎弓切除術のみが行われている（表 1 ).

後側方固定術の固定椎間数は椎弓切除数に一致して 大多数が一椎間または二椎間であり，三椎間は 1 例に 過ぎない.また術前の変性过り，分離过り症について 汇り率を Meyerding の分類に準じて分けると前者では grade I 8 例, grade II 2 例, 後者では grade I 7 例, grade II 3 例で grade I が 20 例中 15 例と大多数を占 めている.

\section{術 後 成 績}

術後成績についてレ線時および臨床像より検討した。

I ） 固定椎間の可動性を認めるものは分離症 12 例 中 2 例, 変性沪り症 10 例中 1 例で, 共に後側方 2 椎間 固定術例であり，いづれも $\mathrm{L}_{4 / 5}$ 椎間に可動性を認めて いるが，このうち現在症状を有するものは分離症例で 間欠性跛行を呈する 1 例のみである.

II）術前のレ線像の完備した症例について固定椎間 より上位椎間板の変化を比較検討すると, 分離症 11 例 中 3 例, 変性过り症 7 例中 1 例, 分離过り症 9 例中 3 例, 計 27 例中 7 例に異常可動性または狭小化を認めて おり, その発生頻度は分離过り症群にやや高率である が現在症状を認めるものは 7 例中 2 例のみで, 時々軽 い腰痛にとどまっている。

III）固定術後，固定部位より上位椎間に disc her-
表 2 術後过り増大頻度

\begin{tabular}{ccc}
\hline \hline DEG. & - LISTHESIS & (対象 7 例) \\
& 1 GRADE & $4 / 5$ 例 \\
2 GRADE & $1 / 2$ \\
LYSIS + LISTHESIS & (対象 9例) \\
1 GRADE & $3 / 7$ 例 \\
& 2 GRADE & $(1) / 2$ \\
( ) 例はLAMINECTOMYのみ, 他はP. L. F.例
\end{tabular}

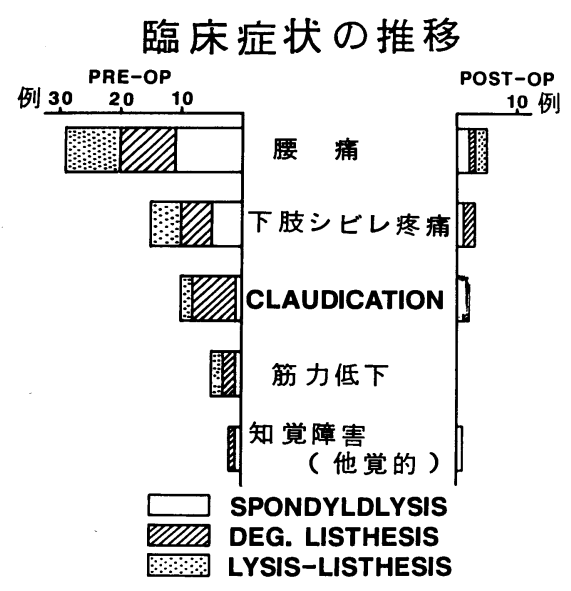

nia, canal stenosis を生じ治療を行った症例は各 1 例 づつ認められており，これらは共に分離症例で，また 調査時 claudication を訴える症例が分離症群の 2 例に 認められている。

IV) 过り率からみた残存症状では変性过り, 分離之一 り症とも grade I の症例に認められており, 过りの程 度と残存症状とは必ずしも一致しないように思われる。

V） 変性过り症 7 例と分離过り症 9 例について術前 と調査時のレ線像を比較し，5\%以上の过り率の増大 をみると, 変性过り症では 7 例中 5 例に, 分離过り症 9 例中 4 例に过り率の悪化が認められており, 分離之二 り症で椎弓切除術のみの 1 例を除き他はすべて椎弓切 除術に後側方固定術を行ったものであり, 変性过り症 群に过り増大の高い傾向がうかがえ，ことに椎弓切除 術のみの症例では，この危険性が大と云える（表 2 ）.

VI）臨床症状の推移では総体的にほぼ満足すべき結 果であるが, 個々の症状についてみると, 腰痛 $17.2 \%$, 下肢のシビレ感, claudication は夫々 $20 \%$ に認められ, 中でも claudication は術後数年して新たに発現したも のであり，すべて分離症の症例である．したがって疾 患別の J. O. A. score では変性过り症, 分離过り症群は 
すべて優の成績に対し, 分離症群では優は $66.7 \%$ と三 群のうちでもっとも悪く，可の 3 例は再手術を含めた claudication の症例であり，良の 1 例は固定隣接椎間 板にへルニアの発生を認めたものである（表 3 ).

\section{考察}

不安定性腰椎の代表的三疾患群について術後平均 10 年の follow-up を行い, 疾患により後側方固定術または 椎弓切除術に後側方固定術を加えることにより，ほぼ 満足すべき結果を得ることが判明した。しかし症例の 中には術後経過と共に他椎間に新たなへルニアの発生 や脊柱管狭窄症状を惹起する例も散見され，固定術患 者の長期 follow の必要性を示唆するものと考える.最 近 Goel らは変性椎間板が隣接椎間に stress の増大を もたらす原因になることを述べているが，固定隣接椎 間にも姿勢や運動により過大な stress の増大とその影 響は当然考えられるところであり，その結果として新 たに脊柱管狭窄症や椎間板変性を生じることが危惧さ れる。ことに分離症群にかかる隣接あるいは上位椎間 に障害を生じる症例が他の二疾患群に比べ多い理由の 一つとして, 手術時の平均年令が低く術後の活動性や 活動期間も関与していることも考えられよう.

また过り症群では術後过りの増大が認められるもの が $56.3 \%$ \%あり,なかでも変性过り症群に頻度が高い 傾向を示しているが，かかる椎弓切除術に後側方固定 を併用した場合，移植骨片の骨瘾合が完成するまで， ある程度の过りの増大の危険性があることを示してお り，この点 Instrumentation の使用も早期離床の利点 と共に充分考慮されるべきと思われる ${ }^{1)}$
結語

分離症, 変性沪り症, 分離沪り症について平均 10 年 1 力月の術後成績を調查し, ほぼ満足すべき結果を得 たが，分離症群では他椎間にへルニア，脊柱管狭窄症 状を新たに呈する頻度が他の二疾患群に比べやや成績 不良であった。また迄り症群では術後过りの増大をみ るものがあり注意を要すると考える。

\section{参 考 文 献}

1）金田清志・他：腰椎分離过り症に対するspinal instrumentation, 臨床整外, $17: 400-410 ， 1982$.

2）久保田政臣・他 : Degenerative Spondylolisthesis に おける手術症例の検討,整形外科, $33: 1813-1819,1982$ 。

3）茂手木三男・他：脊椎分離过り症に対する後方固定 術, 臨床整外, $17: 569-578,1982$.

4）小田裕胤・他：春椎分離症, 脊椎过り症の予後調査, 臨床整外, $17: 340-347,1982$.

5）小野村敏信・他：泰椎分離过り症の手術成績, 災害医 学, $15: 944-952,1972$.

6）竹光義治・他：脊椎分離症, 过り症特集, 臨床整外, $17: 311-314,1982$.
質 問
山口大学 小田 裕胤

変性シり症で術後过り増強の頻度が多いとのことで すので今回の調查より今後どういう術式を選ばれます か.

\section{解 答 長崎市立市民病院 江川 正}

変性汇り症で殊に椎弓切除術を併用した後側方固定 術の場合，比較的簡単な Instrumentation の併用（例 えば Wisconsin' Rod 固定法や Knodt' Rod 法など)が 望ましいのではないかと考えます。 